\title{
Environment and Sports
}

\author{
*Dr. Sharmila Dogra \\ *Assistant Professor, Ramdeobaba College of Engineering and Management Nagpur (M-S)-INDIA.
}

\begin{abstract}
Most of us know from personal experience that environmental factors can affect how you feel and perform your daily tasks. For example, when you step outside on a hot and humid day, you may immediately notice an elevation in temperature, the "heavy" quality of the air, and stickiness against your skin. But did you know that factors like the weather can have a physiological affect on your body. Environmental factors like extreme heat or cold, high altitude and air pollution can elevate heart rates, make it harder to breathe, and impair the ability to exercise. A general understanding of how environmental factors can influence your overall well-being and daily task performance is important for everyone; young or old, fit or unfit. This segment discusses recent physiological research and findings that delve into how the body adapts to short-term (acute) and long term (chronic) exposure to these environmental factors, specifically temperature, altitude and air pollution. The purpose of the present study was to find out that on which game the factor affect most. To accomplish the purpose of the study samples of 100 International level sportsmen's from athletics, hockey, weightlifting, Wrestling \& Shooting were taken. A tool for collection of data was questionnaire method. These questionnaires were sent to the sportsmen of related games. After receiving the responses of questionnaire game wise distribution of raw data was done and for analyses of that data percentage method was used and result were derived. Result revealed that Environment factor affect on sports performance.
\end{abstract}

\section{Introduction}

It is important for all individuals to understand how the body reacts to the environment. This knowledge will lead to smarter, safer, activity outdoor and increased awareness of physiological stress incurred by one's surroundings. Physiologists will continue to study how external factors affect us internally and how we can best adapt to the world around us. Season is considered as specific period of the year characterized by distinctive temperature rainfall, vegetation and the life, which occur at different times in different regions and is determined by the position of the earth in relation to the sun.

\section{Methodology:}

To accomplish the purpose of the study samples of 100 International level sportsmen's from athletics, hockey, weightlifting, Wrestling \& Shooting were taken. A tool for collection of data was questionnaire method. Questionnaire was separately designed by researcher with the help of experts in the field. Reliability of questionnaire was found to be 0.79 . Questionnaire for sportsmen contained two parts A \& B. Part A contains Bio-data \& instructions \& part B contains questionnaire which was related to Environmental factor. Addresses of the sportsmen's were collected from renowned state level association and on the basis of those addresses questionnaire was sent to the players by post.

\section{Statistical Analysis}

The main object of the study was to locate the effect of Environmental factor on sports performance at International level. After receiving the responses of the questionnaire game wise distribution of raw data was done $\&$ on the basis of that it was evaluated percentage wise.

Table - 1 Table Showing Game wise percentage distribution of Environmental factors affecting Sports performance.

\begin{tabular}{|c|c|c|}
\hline Games & Response & Environment \\
\hline \multirow{2}{*}{ Athletics } & Yes & 79.00 \\
\cline { 2 - 3 } & No & 21.00 \\
\hline \multirow{2}{*}{ Hockey } & Yes & 71.35 \\
\cline { 2 - 3 } & No & 28.65 \\
\hline \multirow{2}{*}{ Weight lifting } & Yes & 47.30 \\
\cline { 2 - 3 } & No & 52.70 \\
\hline \multirow{2}{*}{ Wrestling } & Yes & 81.18 \\
\cline { 2 - 3 } & No & 18.82 \\
\hline \multirow{2}{*}{ Shooting } & Yes & 64.35 \\
\cline { 2 - 3 } & No & 35.65 \\
\hline
\end{tabular}




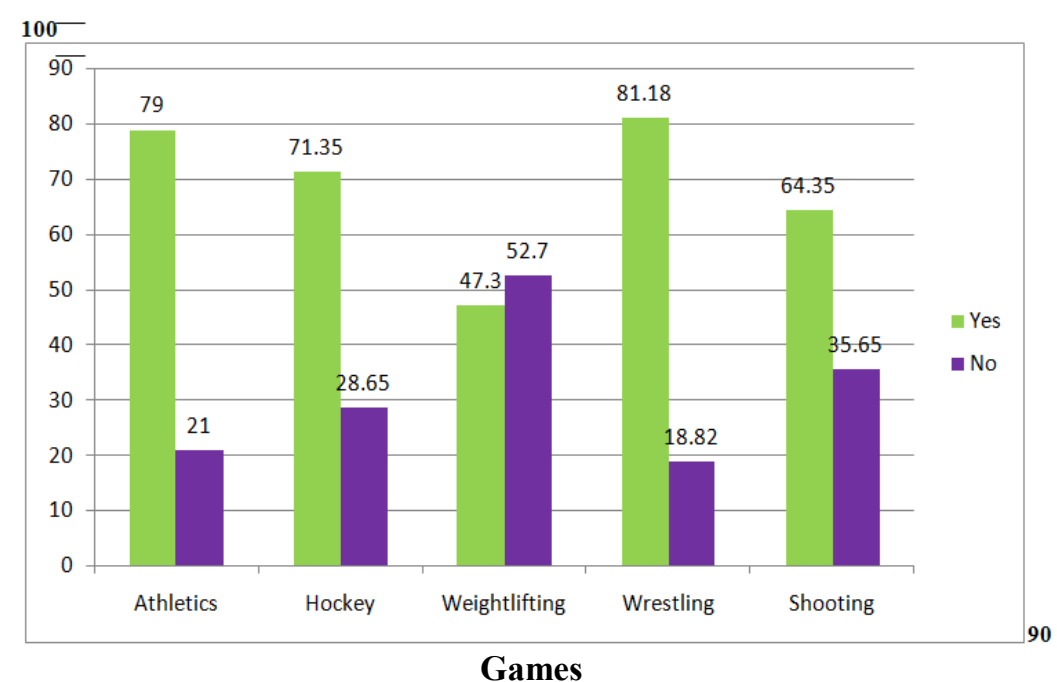

\section{Findings}

Game wise effect of Environmental factor on sports performance revealed that the factor is affecting $79.00 \%$ to athletes, $71.35 \%$ to hockey players, $47.30 \%$ to weight lifters, $81.18 \%$ to Wrestlers \& $64.35 \%$ to Shooters. Overall Environmental factor was known to have found most effective on Wrestling.

\section{Discussion}

On the bases of present findings researcher conclude that Environmental factor affect the performance of sportsmen at International level. It is very well could be understood that this factor is accountable for poor sports performance in the said areas.

\section{References}

[1]. Ross A. Mc Farland, "Temperature and Humidity", Encyclopedia of Sports Sciences and Medicine. (London : Mac Millan \& Co. 1971) P. 876.

[2]. Environmental Factor American Physiological Society, google.com 2005.

[3]. Webster's Dictionary of the English Language, Fourth Indian Reprint, Surjeet Publications, Delhi, 1903 p. 1356.

[4]. Rummel Rose Mary' "Individual and Team Bio-Rhythms and Performances in the 1975 AIAW National Basketball Championship", NAGWS Research Reports, Volume II, AAHPER Washington 1977 p. 24.

[5]. P.K. Pandey, Sports Medicine, Khel Sahitya Kendra, New Delhi, 1998, Pp. 299-302. 